\title{
Efeito da combinação entre carbendazim e inoculantes formulados com polímeros sobre Bradyrhizobium sp. em sementes de caupi
}

\section{Effect of the combination between carbendazim and inoculants formulated with polymers on Bradyrhizobium sp. in cowpea seeds}

Delineide Pereira Gomes ${ }^{1 *}$, Thiago Palhares Farias ${ }^{1}$, Vanessa Cristina M. Reis ${ }^{1}$, Luciene Ferreira dos Santos ${ }^{1}$, Érica Garcia França ${ }^{1}$, Jean Magalhães da Silva ${ }^{2}$, Sylvia Leticia O. Silva ${ }^{1}$, Maria Nasaret M. Moraes Segunda ${ }^{3}$

\section{RESUMO}

Apesar dos resultados promissores dos inoculantes no feijão caupi, diversos fatores influenciam a eficiência dessa biotecnologia, tais como formulações inadequadas e condições de inoculação. Além disso, o tratamento com fungicidas associado aos inoculantes pode afetar a sobrevivência do rizóbio nas sementes. Sendo assim, o objetivo geral foi avaliar a sobrevivência de um rizóbio em sementes de caupi tratadas com o fungicida carbendazim e com inoculantes líquidos formulados com os polímeros goma xantana e carboximetilcelulose (CMC). Um lote de sementes de caupi da cultivar BRS Aracê foi inoculado com a estirpe UFLA 03-84, eficiente na simbiose com caupi (Bradyrhizobium sp.). Essa estirpe foi formulada com auxilio dos polímeros goma Xantana e CMC. Os polímeros foram formulados em diferentes concentrações. Uma vez obtidas as formulações, essas foram associadas ao fungicida a base de carbendazim, na dose recomendada. A sobrevivência da estirpe, em cada formulação, foi avaliada aos 0 , 1, 2, 3, 4, 12, 24, 96, 192 e 768 horas de armazenamento das sementes tratadas. Os polímeros foram formulados em dez concentrações, em três repetições. O número de células viáveis foi determinado através da contagem de unidades formadoras de colônias (UFC), usando o método de diluições seriadas. A goma xantana nas concentrações de 0.025 a $1.0 \mathrm{~g} / \mathrm{L}$ proporcionou, para a maioria dos períodos de armazenamento das sementes tratadas, bons valores quanto a UFC. Com relação ao CMC, concentrações a partir de $1.25 \mathrm{~g} / \mathrm{L}$ de CMC proporcionaram bons valores de UFC, em vários períodos de armazenamento das sementes tratadas. Em geral, com o uso dos polímeros não se obteve um padrão de crescimento no número de células viáveis da estirpe avaliada, para as concentrações e períodos de armazenamento das sementes tratadas nas condições do estudo.

Palavras-chave: Vigna unguiculata (L.) Walp; Rizóbio; Fungicida; Biopolímeros

\section{ABSTRACT}

Despite the promising results of inoculants in cowpea, several factors influence the efficiency of this biotechnology, such as inadequate formulations and inoculation conditions. Furthermore, treatment with fungicides associated with inoculants can affect the survival of rhizobia in seeds. Thus, the general objective was to evaluate the survival of a rhizobia in cowpea seeds treated with the fungicide carbendazim and with liquid inoculants formulated with the polymers Xanthan gum and Carboxymethylcellulose (CMC). A lot of cowpea seeds of cultivar BRS Aracê was inoculated with the

\footnotetext{
${ }^{1}$ Instituto Federal do Maranhão, IFMA, Campus São Luis

*E-mail: delineide.gomes@ifma.edu.br

${ }^{2}$ Instituto Federal do Maranhão, IFMA, Campus São Raimundo das Mangabeiras.

${ }^{3}$ Instituto Federal do Maranhão, IFMA - Campus Açailândia
} 
UFLA 03-84 strain, efficient in symbiosis with cowpea (Bradyrhizobium sp.). This strain was formulated with the aid of Xanthan Gum and CMC polymers. Polymers were formulated at different concentrations. Once the formulations were obtained, they were associated with carbendazim-based fungicide, at the recommended dose for seed treatment. The strain survival, in each formulation, was evaluated at $0,1,2$, $3,4,12,24,96,192$ and 768 hours of storage of the treated seeds. The polymers were formulated in ten concentrations, in three repetitions. The number of viable cells was determined by counting colony forming units (UFC) using the serial dilution method. Xanthan gum at concentrations from 0.025 to 1.0 $\mathrm{g} / \mathrm{L}$ provided, for most of the storage periods of treated seeds, good values for UFC. Regarding CMC, concentrations from $1.25 \mathrm{~g} / \mathrm{L}$ of CMC provided good values of UFC, in several storage periods of the treated seeds. In general, with the use of polymers a growth pattern was not obtained in the number of viable cells of the evaluated strain, for the concentrations and storage periods of the seeds treated.

Keywords: Vigna unguiculata (L.) Walp; Rhizobium; Fungicide; Biopolymers

\section{INTRODUÇÃO}

O caupi, também conhecido como feijão de corda, macassar ou fradinho, é uma fabácea de grande relevância econômica e social, principalmente no Norte e Nordeste do Brasil. Constitui-se em um dos grãos mais consumidos nessas regiões, por ser uma importante fonte protéica, com minerais e fibras. Trata-se de uma cultura que gera emprego e renda a produtores, cujo crescimento vem expandindo nas diferentes regiões produtoras de grãos, além de ser considerada cultivo de subsistência para o agricultor familiar. O caupi apresenta características que facilitam seu cultivo, como ciclo rápido, rusticidade, tolerância a déficit hídrico e adaptação a solos pouco férteis (ZILLI et al., 2009; COSTA et al., 2018; SOUZA, 2017).

Segundo a CONAB (2020), o Maranhão apresentou uma produtividade média de feijão- caupi de $534 \mathrm{~kg} \cdot \mathrm{ha}^{-1}$ na primeira safra 2019/2020, porém, abaixo das produtividades alcançadas por outros estados, tais como Mato Grosso (que já atingiu $1.201 \mathrm{~kg} \mathrm{ha}^{-1}$ ), Tocantins e Minas Gerais. Isso tem sido atribuído à vários fatores, tais como a falta de água em função da estiagem e de temperaturas elevadas (SILVA et al. 2012), emprego de cultivares tradicionais pouco produtivas, baixa tecnificação no cultivo (FREIRE FILHO et al, 2005; MONTEIRO et al., 2012; GUIMARÃES et al., 2020) e à menor fertilidade dos solos ou disponibilidade de nutrientes, particularmente o nitrogênio (REIS et al, 2018; GUIMARÃES et al., 2020).

Vários são os resultados de pesquisa que mostram os ganhos em produtividade que o caupi pode alcançar após inoculação das sementes com bactérias fixadoras de nitrogênio (ZILLI et al., 2009; ALMEIDA et al., 2010; FARIAS, 2014). Estirpes 
testadas já apresentaram boa eficiência na fixação biológica do nitrogênio (FBN), parte delas com produção de biomassa equivalente a $90 \%$, ou mais, da biomassa produzida pelo tratamento com nitrogênio mineral (CHAGAS JUNIOR et al., 2010).

Alguns inoculantes líquidos que existem no mercado buscam uma alternativa técnica viável ao uso da turfa, pois procuram reduzir os custos de produção e facilitar a aplicação do produto na semente no momento da semeadura, bem como manter a sobrevivência e a eficiência do rizóbio em condições de campo (SCHUH, 2005). No entanto, as diferentes condições de inoculação, tratamentos químicos nas sementes e o tempo de exposição a esses produtos devem ser estudados, pois podem afetar a sobrevivência do rizóbio. Pesquisas com outros veículos como gomas naturais, alginatos, entre outros, podem ser promissores como suporte para a produção de inoculantes, destacando-se os polímeros naturais ou sintéticos, os quais possam oferecer características desejadas e manter a viabilidade do rizóbio (SCHUH, 2005). Os inoculantes líquidos podem ser aplicados, tanto sobre as sementes como diretamente no sulco de semeadura. Essas formulações proporcionam distribuição mais uniformizada e apresentam capacidade de aderência mais efetiva (DENARDIN, 2010).

Sabe-se que a aplicação de fungicidas, além de outros agroquímicos sobre as sementes trazem inúmeros benefícios para a produção vegetal. Entretanto, estes produtos podem trazer efeitos negativos sobre o rizóbio nas sementes, podendo prejudicar a interação simbiótica e reduzir a FBN (CAMPO et al., 2003; CAMPOS et al., 2009; SANTOS et al., 2018).

Conforme Cardoso et al. (2019) a interação entre bactérias do gênero Bradyrhizobium com defensivos agrícolas pode alterar a FBN e diminuir a nodulação. Pesquisas ainda pouco esclarecem sobre a interferência que os diferentes defensivos poderiam ter sobre a sobrevivência das bactérias fixadoras de nitrogênio presente nos inoculantes, quanto à sua sobrevivência nas sementes, o que constitui sério obstáculo à adoção destas tecnologias conjuntamente (CARDILLO, 2015; SANTOS et al., 2018).

No feijão caupi ainda são insuficientes os estudos sobre o efeito de fungicidas aplicados no tratamento de sementes sobre o rizóbio presentes nos inoculantes. Os fungicidas podem afetar diretamente na FBN por interferir na atividade da bactéria, podendo causar a sua mortalidade (SANTOS et al., 2018). Portanto, no caso da aplicação de fungicidas, recomenda-se verificar, primeiramente, sua compatibilidade com o rizóbio (CARDILLO, 2015). 
Nesse contexto, o objetivo deste trabalho foi avaliar a sobrevivência de um rizóbio em sementes de feijão caupi tratadas com o fungicida carbendazim e com inoculantes líquidos formulados com os polímeros goma xantana e carboximetilcelulose (CMC), em diferentes concentrações e períodos de armazenamento das sementes tratadas com esses produtos.

\section{MATERIAL E MÉTODOS}

Foram utilizadas sementes da cultivar BRS Aracê, as quais passaram por um tratamento fungicida a base de carbendazim na dose de $200 \mathrm{~mL} / 100 \mathrm{~kg}$ de sementes.

O rizóbio utilizado foi Bradyrhizobium sp. estirpe UFLA03-84, eficiente na simbiose com o feijão-caupi (LACERDA et al., 2004). A estirpe foi cultivada no meio de cultura 79 (FRED; WAKSMAN, 1928) e YMA (VICENT, 1970) (10 g.L ${ }^{-1}$ de manitol, 0,01 g.L $\mathrm{L}^{-1}$ de $\mathrm{K}_{2} \mathrm{HPO}_{4}, 0,04$ g.L ${ }^{-1}$ de $\mathrm{KH}_{2} \mathrm{PO}_{4}, 0,05$ g.L $\mathrm{L}^{-1} \mathrm{MgSO}_{4} 7 \mathrm{H}_{2} \mathrm{O}, 0,01$ g.L $\mathrm{L}^{-1} \mathrm{NaCl}, 0,04$ g.L $\mathrm{L}^{-1}$ de extrato de levedura em pó, 15 g.L $\mathrm{L}^{-1}$ ágar, $\mathrm{pH}$ ajustado a 6,8$7,0)$ a $28^{\circ} \mathrm{C}$.

Foram utilizados os polímeros Goma Xantana e CMC, em diferentes concentrações em massa por volume. Após o preparo, as formulações foram esterilizadas em autoclave a $120^{\circ} \mathrm{C}$. Para a padronização da concentração do inóculo, as estirpes foram inoculadas em Erlenmeyer $(125 \mathrm{~mL})$, durante $72 \mathrm{~h}$, até densidade óptica de 0,05 a $600 \mathrm{~nm}\left(\mathrm{DO}_{600}\right)$, equivalente a $1,5 \times 10^{8} \mathrm{UFC} \cdot \mathrm{mL}^{-1}$ pela escala de McFarland.

Em seguida, uma alíquota de $0,1 \mathrm{~mL}$ do inóculo foi adicionada a frascos de vidro lavados com ácido e esterilizados com meio 79 líquido modificado. Os frascos foram distribuídos em uma incubadora a $110 \mathrm{rpm}$ e $28{ }^{\circ} \mathrm{C}$ para auxiliar a detecção de possíveis contaminações, por alterações em $\mathrm{pH}$ do meio durante a avaliação, tratamentos controles sem inoculação foram mantidos. Alíquotas de $0,1 \mathrm{~mL}$ do inóculo da estirpe UFLA 03-84 foi inoculada em cada uma das formulações (concentrações dos polímeros). Posteriormente, as formulações foram transferidas para tubos de centrifugação em polipropileno fundo cônico, com tampa alongada à prova de vazamentos, com capacidade de $50 \mathrm{~mL}$, esterilizados por radiação gama.

Sementes da cultivar BRS Aracê foram inoculadas em lotes de 200 sementes por tratamento (concentração do polímero $\mathrm{x}$ período de armazenamento), sendo 
selecionadas aleatoriamente do lote, com $500 \mu \mathrm{L}$ de inoculante líquido, em três repetições, sob condições de assepsia e ambiente controlado (capela de fluxo laminar).

Foi utilizado o método das diluições seriadas. Vinte sementes, retiradas aleatoriamente de amostras com 200 sementes de cada tratamento, colocadas no Erlenmeyer contendo $90 \mathrm{~mL}$ de solução salina 0,85\% estéril e agitadas por 15 minutos, sendo considerada inicialmente a diluição de $10^{-1}$. A partir dessa diluição, alíquotas de 1,0 mL de cada formulação foram diluídas sucessivamente até a diluição de $10^{-9}$ (adaptado de FARIAS, 2014; CARDILLO, 2015).

Alíquotas de $20 \mathrm{~mL}$ foram inoculadas em placas de Petri com meio YMA, por meio da técnica de micro gotas, e secas na capela de fluxo laminar durante 20 min antes de ser invertida e depois incubada a $28^{\circ} \mathrm{C}$, por um período de até $144 \mathrm{~h}$. As avaliações foram realizadas em quadruplicatas (adaptado de FARIAS, 2014; CARDILLO, 2015).

O número de células viáveis foram determinados pela contagem de unidades formadoras de colônias (UFC), para cada tratamento, em delineamento inteiramente casualizado (DIC) aos 0, 1, 2, 3, 4, 12, 24, 96, 192 e 768 horas de armazenamento das sementes tratadas com esses produtos. A fórmula utilizada para calcular o numero de unidades formadoras de colônias por milímetro foi:

Unidades formadoras de colônias $\left(U F C \cdot \mathrm{mL}^{-1}\right)=$ Número de Colônias por diluição $\mathrm{x}$ Fator de diluição.

Os dados de UFC foram submetidos à análise de variância e ao teste $F$, utilizando software de análise estatística SISVAR ${ }^{\circledR}$ (FERREIRA, 2011).

Para cada polímero (Goma Xantana e CMC) foi instalado um esquema fatorial com dois fatores, cada um com 10 níveis (ou seja, 10 concentrações x 10 períodos de armazenamento das sementes), com 12 repetições (quadruplicatas) e submetidos ao teste F e ao Teste de Tukey ao nível de $5 \%$ de probabilidade.

\section{RESULTADOS E DISCUSSÃO}

Na Tabela 1 são apresentadas as concentrações dos polímeros obtidas experimentalmente em laboratório, as quais foram utilizadas posteriormente nas formulações (veículos do inoculante) para o tratamento das sementes de caupi. Para a obtenção e escolha das concentrações ideais dos polímeros foram observados 
parâmetros visuais e sensoriais, a fim de se verificar as consistências mais adequadas, considerando a cor, viscosidade e faixa de $\mathrm{pH}$ ideal.

Tabela 1- Concentrações $\left(\mathrm{g} . \mathrm{L}^{-1}\right)$ almejadas de dois polímeros obtidas para o preparo das formulações do rizóbio visando a inoculação de sementes de caupi cv. BRS Aracê.

\begin{tabular}{ccccccccccc}
\hline Polímeros & \multicolumn{10}{c}{ Concentrações $\left(\mathrm{g} . \mathrm{L}^{-1}\right)$} \\
\hline Goma Xantana & 0 & 0.05 & 0.25 & 0.50 & 0.75 & 1.00 & 1.25 & 1.50 & 1.75 & 2.0 \\
\hline CMC & 0 & 0.05 & 0.25 & 0.50 & 0.75 & 1.00 & 1.25 & 1.50 & 1.75 & 2.0 \\
\hline
\end{tabular}

Fonte: Os Autores (2021)

A utilização da goma xantana nas concentrações de 0.25 a 1.0 g.L ${ }^{-1}$ proporcionou, para a maioria dos períodos de armazenamento das sementes tratadas, bons valores quanto de UFC. No entanto, não permitiram obter um padrão de crescimento no número de células viáveis da estirpe estudada, ou seja, não houve um padrão ou tendência de manutenção da estirpe avaliada, nas condições do presente estudo (Tabela 2).

Tabela 2- Sobrevivência de Bradyrhizobium sp. em sementes de caupi cv. BRS Aracê tratadas com carbendazim e submetidas ao inoculante veiculado pela Goma Xantana em diferentes concentrações e períodos de armazenamento das sementes tratadas.

\begin{tabular}{ccccccccccc}
\hline \begin{tabular}{c} 
Concent $\begin{array}{c}\text { UFC } \\
\text { ração } \\
\left(\mathrm{g} . \mathrm{L}^{-1}\right)\end{array}$ \\
\cline { 2 - 12 }
\end{tabular} & $0 \mathrm{~h}^{1}$ & $1 \mathrm{~h}$ & $2 \mathrm{~h}$ & $3 \mathrm{~h}$ & $4 \mathrm{~h}$ & $12 \mathrm{~h}$ & $24 \mathrm{~h}$ & $96 \mathrm{~h}$ & $192 \mathrm{~h}$ & $768 \mathrm{~h}$ \\
\hline 0.0 & $10.5 \mathrm{a}$ & $5.08 \mathrm{~d}$ & $1.41 \mathrm{~b}$ & $4.25 \mathrm{a}$ & $2.66 \mathrm{~b}$ & $9.3 \mathrm{abc}$ & $0.5 \mathrm{c}$ & $0 \mathrm{~b}$ & $0 \mathrm{c}$ & $0 \mathrm{c}$ \\
\hline 0.05 & $3.5 \mathrm{a}$ & $32.9 \mathrm{a}$ & $41.1 \mathrm{a}$ & $6.41 \mathrm{a}$ & $3.4 \mathrm{~b}$ & $14.8 \mathrm{ab}$ & $11.4 \mathrm{abc}$ & $20.5 \mathrm{a}$ & $4.3 \mathrm{c}$ & $12.1 \mathrm{abc}$ \\
\hline 0.25 & $5,8 \mathrm{a}$ & $3.08 \mathrm{~d}$ & $5.91 \mathrm{~b}$ & $0 \mathrm{a}$ & $4.41 \mathrm{~b}$ & $0 \mathrm{c}$ & $9.1 \mathrm{abc}$ & $10.1 \mathrm{ab}$ & $8.6 \mathrm{bc}$ & $16.5 \mathrm{ab}$ \\
\hline 0.5 & $8.1 \mathrm{a}$ & $17.1 \mathrm{bc}$ & $9.91 \mathrm{~b}$ & $1.91 \mathrm{a}$ & $9.9 \mathrm{ab}$ & $19.5 \mathrm{a}$ & $20.8 \mathrm{a}$ & $2.9 \mathrm{~b}$ & $3.83 \mathrm{c}$ & $6.0 \mathrm{bc}$ \\
\hline 0.75 & $5.7 \mathrm{a}$ & $7.0 \mathrm{~d}$ & $0.25 \mathrm{~b}$ & $5.83 \mathrm{a}$ & $7.83 \mathrm{~b}$ & $10 \mathrm{abc}$ & $15.6 \mathrm{ab}$ & $6.66 \mathrm{~b}$ & $19.7 \mathrm{ab}$ & $11.4 \mathrm{abc}$ \\
\hline 1.0 & $0 \mathrm{a}$ & $0 \mathrm{~d}$ & $4.91 \mathrm{~b}$ & $12 \mathrm{a}$ & $22.5 \mathrm{a}$ & $1.5 \mathrm{bc}$ & $0.41 \mathrm{c}$ & $0 \mathrm{~b}$ & $10.4 \mathrm{abc}$ & $3.3 \mathrm{bc}$ \\
\hline 1.25 & $1.5 \mathrm{a}$ & $22.1 \mathrm{ab}$ & $1.08 \mathrm{~b}$ & $1 \mathrm{a}$ & $0.25 \mathrm{~b}$ & $0.16 \mathrm{c}$ & $11.4 \mathrm{abc}$ & $1.0 \mathrm{~b}$ & $12.8 \mathrm{abc}$ & $19.7 \mathrm{a}$ \\
\hline 1.5 & $0 \mathrm{a}$ & $10.2 \mathrm{bcd}$ & $0.25 \mathrm{~b}$ & $1.33 \mathrm{a}$ & $0.08 \mathrm{~b}$ & $8.5 \mathrm{abc}$ & $1.0 \mathrm{c}$ & $0 \mathrm{~b}$ & $12.3 \mathrm{abc}$ & $3.0 \mathrm{bc}$ \\
\hline 1.75 & $0 \mathrm{a}$ & $1.58 \mathrm{~d}$ & $1.08 \mathrm{~b}$ & $11 \mathrm{a}$ & $1.25 \mathrm{~b}$ & $0.25 \mathrm{c}$ & $5.4 \mathrm{bc}$ & $1.8 \mathrm{~b}$ & $0 \mathrm{c}$ & $11.6 \mathrm{abc}$ \\
\hline 2.0 & $0.2 \mathrm{a}$ & $6.08 \mathrm{~d}$ & $2.50 \mathrm{~b}$ & $2.66 \mathrm{a}$ & $1.50 \mathrm{~b}$ & $0.08 \mathrm{c}$ & $6.3 \mathrm{bc}$ & $1.0 \mathrm{~b}$ & $22.9 \mathrm{a}$ & $13.7 \mathrm{ab}$ \\
\hline \multicolumn{7}{c}{ *UFC- Unidade Formadora de Colônias, média obtida na diluição de $10^{-9} ;$} \\
\\
\hline
\end{tabular}

Fonte: Os Autores (2021)

A sobrevivência de rizóbios em formulações veiculadas por polímeros tais como a goma xantana, pode ser atribuída à propriedade de "encapsular" células bacterianas, 
protegendo-as de estresses ambientais, e, portanto mantendo a sua viabilidade (DENARDIN e FREIRE, 2000; SANTOS, 2011).

Os tratamentos foram submetidos em um esquema fatorial, sendo que na análise da variância (dados não mostrados) não houve interação significativa entre os fatores estudados (concentração do polímero x período de armazenamento das sementes tratadas), e por isso, sendo analisadas apenas as médias das concentrações dos polímeros dentro de cada período de armazenamento das sementes tratadas com os polímeros + fungicida (Tabelas 2 e 3). Pela ausência de tendência no padrão de crescimento da bactéria, também não houve a possibilidade do uso da análise de regressão.

Em várias concentrações do $\mathrm{CMC}$, também não houve um padrão no crescimento ou na manutenção da viabilidade celular da estirpe avaliada. Algumas concentrações como 0.75 e 1.25 g.L $\mathrm{L}^{-1}$ do CMC mantiveram uma boa viabilidade celular até o tempo máximo de $768 \mathrm{~h}$ após o tratamento das sementes com o fungicida. Concentrações a partir de 1.25 g.L $\mathrm{L}^{-1}$ de CMC proporcionaram bons valores de UFC do rizóbio estudado, em vários períodos de armazenamento das sementes (Tabela 3).

Tabela 3 - Sobrevivência de Bradyrhizobium sp. em sementes de caupi cv. BRS Aracê tratadas com carbendazim e submetidas ao inoculante veiculado pelo Carboximetilcelulose (CMC) em diferentes concentrações e períodos de armazenamento das sementes tratadas.

\begin{tabular}{|c|c|c|c|c|c|c|c|c|c|c|}
\hline \multirow{2}{*}{$\begin{array}{l}\text { Concentr } \\
\text { ação do } \\
\text { polímero } \\
\left(\text { g.L } L^{-1}\right)\end{array}$} & \multicolumn{10}{|c|}{ UFC*/período de armazenamento das sementes (horas) } \\
\hline & $0 \mathrm{~h}^{1}$ & $1 \mathrm{~h}$ & $2 \mathrm{~h}$ & $3 \mathrm{~h}$ & $4 \mathrm{~h}$ & $12 \mathrm{~h}$ & $24 \mathrm{~h}$ & $96 \mathrm{~h}$ & $192 \mathrm{~h}$ & $768 \mathrm{~h}$ \\
\hline 0.0 & $3.8 \mathrm{a}$ & $5.6 \mathrm{a}$ & $0.6 \mathrm{~b}$ & $0.1 \mathrm{c}$ & $8.4 \mathrm{ab}$ & $13 \mathrm{a}$ & $3.0 \mathrm{a}$ & $7.6 \mathrm{c}$ & $3.7 \mathrm{~b}$ & $5.4 \mathrm{bc}$ \\
\hline 0.05 & $0 \mathrm{a}$ & $0.3 \mathrm{a}$ & $0 \mathrm{~b}$ & $0.3 \mathrm{c}$ & $1.0 \mathrm{~b}$ & $0 \mathrm{c}$ & $0 \mathrm{a}$ & $0 \mathrm{c}$ & $0.6 \mathrm{~b}$ & $1.6 \mathrm{c}$ \\
\hline 0.25 & $2.0 \mathrm{a}$ & $0.4 \mathrm{a}$ & $0.7 \mathrm{~b}$ & $2.5 \mathrm{ab}$ & $0.5 \mathrm{~b}$ & $8.7 \mathrm{abc}$ & $4.4 \mathrm{a}$ & $0 \mathrm{c}$ & $1.3 \mathrm{~b}$ & $15.3 \mathrm{a}$ \\
\hline 0.5 & $3.0 \mathrm{a}$ & $4.0 \mathrm{a}$ & $2.0 \mathrm{~b}$ & $2.0 \mathrm{ab}$ & $1.0 \mathrm{~b}$ & $1.1 \mathrm{bc}$ & $0 \mathrm{a}$ & $4.3 \mathrm{c}$ & $0.3 \mathrm{~b}$ & $0.5 \mathrm{c}$ \\
\hline 0.75 & $0 \mathrm{a}$ & $0.5 \mathrm{a}$ & $0.8 \mathrm{~b}$ & $1.7 \mathrm{ab}$ & $0.08 \mathrm{~b}$ & $10.4 \mathrm{ab}$ & $5.3 \mathrm{a}$ & $1.3 \mathrm{c}$ & $0.08 \mathrm{~b}$ & $1.5 \mathrm{c}$ \\
\hline 1.0 & $0.6 \mathrm{a}$ & $0.7 \mathrm{a}$ & $0.2 \mathrm{~b}$ & $0 \mathrm{c}$ & $0 \mathrm{~b}$ & $5.5 \mathrm{abc}$ & $0 \mathrm{a}$ & $0.5 \mathrm{c}$ & $3.5 \mathrm{~b}$ & $3.7 \mathrm{c}$ \\
\hline 1.25 & $6.2 \mathrm{a}$ & $4.7 \mathrm{a}$ & $12.4 \mathrm{a}$ & $2.1 \mathrm{ab}$ & $1.9 \mathrm{~b}$ & $0.3 \mathrm{c}$ & $7.5 \mathrm{a}$ & $30.5 \mathrm{a}$ & $24.7 \mathrm{a}$ & $17.1 \mathrm{a}$ \\
\hline 1.5 & $1.7 \mathrm{a}$ & $1.5 \mathrm{a}$ & $0.6 \mathrm{~b}$ & $1.5 \mathrm{ab}$ & $15.1 \mathrm{a}$ & $0.1 \mathrm{c}$ & $0.5 \mathrm{a}$ & $23.2 \mathrm{ab}$ & $29.2 \mathrm{a}$ & $8.0 \mathrm{abc}$ \\
\hline 1.75 & $0.4 \mathrm{a}$ & $4.3 \mathrm{a}$ & $8.2 \mathrm{ab}$ & $0.5 \mathrm{c}$ & $0.2 \mathrm{~b}$ & $3.3 \mathrm{abc}$ & $9.1 \mathrm{a}$ & $3.1 \mathrm{c}$ & $3.6 \mathrm{~b}$ & $13.7 \mathrm{ab}$ \\
\hline 2.0 & $2.2 \mathrm{a}$ & $0.2 \mathrm{a}$ & $2.7 \mathrm{ab}$ & $10.7 \mathrm{a}$ & $3.3 \mathrm{~b}$ & $9.5 \mathrm{abc}$ & $1.1 \mathrm{a}$ & $17.5 \mathrm{~b}$ & $9.5 \mathrm{~b}$ & $2.2 \mathrm{c}$ \\
\hline
\end{tabular}
Fonte: Os Autores (2021)

Estudos com o CMC mostram este ser um polímero bastante promissor quanto a sua utilização em formulações poliméricas, como no caso das misturas de CMC com 
amido, visando a utilização como suporte para inoculantes (RHOR, 2007; FERNANDES JÚNIOR et al., 2006).

Em feijoeiro comum, Kintschev et al. (2014) verificaram que a sobrevivência de duas estirpes de rizóbio (Rhizobium tropici + Rhizobium freirei) inoculadas em sementes foram afetadas pela aplicação de diferentes fungicidas, principalmente por aqueles com modo de ação por contato. Na presente pesquisa com sementes de caupi foi utilizado um fungicida sistêmico, no caso o carbendazim, o qual é amplamente utilizado no tratamento de sementes de feijão comum. Sabe-se que os fungicidas sistêmicos são menos tóxicos, quando comparado aos fungicidas de contato, assim, é preferível utilizar produtos com menor toxicidade, pois este fator também pode interferir negativamente na sobrevivência das bactérias fixadoras de nitrogênio.

Santos et al. (2018), em estudo de compatibilidade do inseticida tiametoxan com os fungicidas sistêmicos tiofanato metílico e fluazinam sobre rizóbios, verificaram que estes produtos foram compatíveis no tratamento de sementes de caupi, pois não inibiram o crescimento da estirpe INPA 03-11B.

Nestas pesquisas e no presente trabalho é oportuno evidenciar a recomendação de Barbosa e Gonzaga (2012) de manter o inoculante em contato com o fungicida durante o menor tempo possível na semente, ou seja, é desejável um menor tempo de armazenamento das sementes tratadas com esses produtos, pois isto pode reduzir a qualidade fisiológica das sementes, bem como afetar a sobrevivência do rizóbio nas mesmas, e por conseqüência prejudicar a FBN. No presente trabalho, bons valores de UFC foram obtidos em períodos de armazenamento variáveis, variando de 0 a $32 \mathrm{~h}$ das sementes tratadas com produtos estudados.

\section{CONCLUSÓES}

Na análise da sobrevivência da estirpe UFLA 03-84 de Bradyrhizobium sp. em sementes de caupi cv. BRS Aracê não ocorreu um padrão de crescimento no número de células viáveis do microrganismo em função das concentrações dos polímeros goma xantana e CMC nos períodos de armazenamento das sementes tratadas com essas formulações e com o fungicida carbendazim.

Mesmo sem a observação desse padrão de crescimento e ausência de interações significativas, a combinação do inoculante veiculado pelos polímeros goma xantana e 
CMC com o carbendazim permite a sobrevivência da estirpe avaliada, o que foi visto em muitas concentrações dos polímeros estudados e em alguns dos períodos de armazenamento das sementes tratadas com esses produtos.

\section{REFERÊNCIAS}

ALMEIDA, A.S., CARVALHO, I.D., CRISTIANE, T.M.AA.; VILLELA, F.A. Bioativador no desempenho fisiológico de sementes de arroz. Revista Brasileira de Sementes, 2011. v.33, n.3, p. 501-510.

BARBOSA, F.R.; GONZAGA, A. C. O. Informações técnicas para o cultivo do feijoeiro-comum na Região Central-Brasileira: 2012-2014. Santo Antônio de Goiás: Embrapa Arroz e Feijão, (Documentos, 272), 2012. 247 p.

CAMPO, J.R. et al. Compatibilidade de aplicação de inoculantes com defensivos agrícolas e micronutrientes. In: CAMPO, C. B. H.; SARAIVA, O. F. (Org.).

Resultados de pesquisa da Embrapa Soja-2002. Londrina: Embrapa Soja, 2003. p. 20-38. (Documentos, 216).

CAMPO, R.J.; ARAUJO, R. S.; HUNGRIA, M. Nitrogen fixation with the soybean crop in Brazil: Compatibility between seed treatment with fungicides and bradyrhizobial inoculants. Symbiosis, v. 48, p.154-163, 2009.

CARDILLO, B.E. da S. Compatibilidade de fungicida via semente e fixação simbiótica em feijoeiro-comum. 2015. 122 p. Dissertação (Mestrado em Agronomia/Fitotecnia) -Universidade Federal de Lavras, Lavras, 2015.

CARDOSO, M.B.; PASCUTTI, T.M.; FERREIRA FILHO, P.J.; PRADO, E.P; GUERREIRO, J.C. Associação da bactéria Bradyrhizobium japonicum com agrotóxicos utilizados no tratamento de sementes de soja. Brazilian Journal of Development, Curitiba, v. 5, n. 10, p. 18526-18537, 2019.

CHAGAS JR, A.F.; RAHMEIER, R.; FIDELIS, R.R.; SANTOS, G.R. E CHAGAS, L.F.B. Eficiência agronômica de estirpes de rizóbio inoculadas em feijão-caupi no Cerrado, Gurupi-TO. Revista Ciência Agronômica, v.41, p.709-714, 2010.

COSTA, E.M. et al. Resposta de duas cultivares de feijão-caupi à inoculação com bactérias fixadoras de nitrogênio em ambiente protegido. Agrária - Revista Brasileira de Ciências Agrárias. v.9, n.4, p.489-494, 2014.

DENARDIN, N.D.; FREIRE, J.R.J. Assessment of polymers for the formulation of legume inoculants. World Journal of Microbiology and Biotechnology, v.16, p.215$217,2000$.

DENARDIN, N.D. Fixação biológica de nitrogênio em interação com produtos fitossanitários, químicos e biológicos, por leguminosas. Avanços no tratamento e recobrimento de sementes. Informativo ABRATES, v. 20, n. 3, p. 62-69. 2010. 
FARIAS, T.P. Eficiência agronômica de estirpes de rizóbio em feijão-caupi cultivado em áreas do Maranhão. 2014. 107 p. Dissertação (Mestrado em Ciência do Solo) - Universidade Federal de Lavras, Lavras, 2014.

FERNANDES JÚNIOR, P.I. Composições poliméricas a base de carboximetilcelulose (CMC) e amido como veículos de inoculação de rizóbio em leguminosas. 2006. Dissertação (Mestrado em Ciência do Solo). Universidade Federal Rural do Rio de Janeiro, Seropédica, 2006.

FERREIRA, D.F. SISVAR: a computer statistical analysis system. Ciência e Agrotecnologia, Lavras, v. 35, n. 6, p. 1039-1042, 2011.

FRED, E.B.; WAKSMAN, S. A. Laboratory manual of general microbiology. 1. ed. New York: McGraw W-Hill Book Company, 1928. v. 1

FREIRE FILHO, F.R.; LIMA, J.A. de A.; RIBEIRO, V.Q. Feijão-caupi: Avanços tecnológicos. Ed. Brasília-DF. Embrapa Informática, 2005. 519 p

GUIMARÃES, D.G et al. Desempenho da cultivar de feijão-caupi brsnovaera sob níveis de irrigação e adubação em ambiente protegido. Cultura Agronômica, Ilha Solteira, v.29, n.1, p. 61-75, 2020.

KINTSCHEV, M.R.; GOULART, A.C.P.; MERCANTE, F.M. Compatibilidade entre a inoculação de rizóbios e fungicidas aplicados em sementes de feijoeiro-comum. Summa Phytopathologica, Botucatu, v. 40, n. 4, p. 338-346, 2014.

MONTEIRO, F.P.R.; CHAGAS JUNIOR, A.F.; REIS, M. R.; SANTOS, G.R.; CHAGAS, L.F. B. Efeitos de herbicidas na biomassa e nodulação do feijão-caupi inoculado com rizóbio. Revista Caatinga, Mossoró, v. 25, n. 3, p.44-51, 2012.

REIS, V.R.R.; SOUZA, L.R.S.; VIEIRA, G.L.S.; COELHO, K.B.S.; FILHO, A.S.C.; SILVA, M. R.M. Crescimento vegetativo do feijão-caupi com inoculante alternativo. Revista Verde de Agroecologia e Desenvolvimento Sustentável, v. 13, n. 4, p. 466-471, 2018.

RHOR, T.G. Estudo reológico da mistura carboximetilcelulose/amido e sua utilização como veículo de inoculação bacteriano. 2007. 124f. Dissertação (Mestrado em Engenharia Química.)- Universidade Federal Rural do Rio de Janeiro, Seropédica, 2007.

SANTOS, A.A. Produção de polissacarídeos visando obter insumos biológicos de interesse para agricultura. 2011. 58f. Dissertação (Mestrado em Ciência do Solo). Universidade Federal Rural de Pernambuco, Recife, 2011.

SANTOS, M.M.S.; ROCHA, W.S.; SILVA JUNIOR, F.R. CHAGAS JUNIOR, A F; LOPES, R.R. Compatibilidade de tratamentos de sementes e rizóbio in vitro e em casa de vegetação no feijão- caupi. Tecnologia \& Ciência agropecuária, v.12, n.1, p. 15-21, 2018 . 
SILVA, H.A.P. da; GALISA, P. de S.; OLIVEIRA, R.S. da S.; VIDAL, M.S.; SIMÕES-ARAÚJO, J.L. Expressão gênica induzida por estresses abióticos em nódulos de feijão-caupi. Pesquisa Agropecuária Brasileira, Brasília, v.47, n.6, p.797-807. 2012.

SCHUH, C.A. Biopolímeros como suporte para inoculantes. Dissertação de Mestrado, Programa de Pós-Graduação em Microbiologia Agrícola e do Ambiente, Faculdade de Agronomia, Universidade Federal do Rio Grande do Sul. Porto Alegre, RS, Brasil. (81p.). 2005.

SOUZA, D.A. Germinação e desenvolvimento inicial de Vigna unguiculata (L.) Walp. inoculada com bactérias diazotróficas. 2017. Trabalho de conclusão de curso (Graduação de Tecnologia em Agroecologia) - Centro de Ciências Agrárias, Ambientais e Biológicas da Universidade Federal do Recôncavo da Bahia, BA, 2017.

VINCENT, J.M. A manual for the practical study of the root-nodule bacteria. London: International Biological Programme, 1970. 